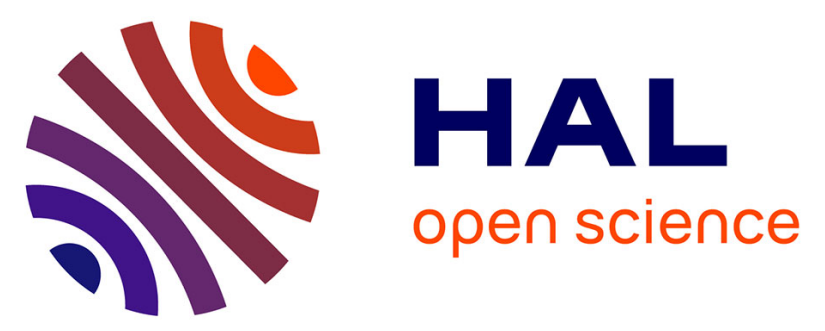

\title{
Breast Health Problems Are Rare in Both HIV-Infected and HIV-Uninfected Women Who Receive Counseling and Support for Breast-Feeding in South Africa.
}

\author{
Ruth M. Bland, Renaud Becquet, Nigel C. Rollins, Anna Coutsoudis, Hoosen
}

M. Coovadia, Marie-Louise Newell

\section{To cite this version:}

Ruth M. Bland, Renaud Becquet, Nigel C. Rollins, Anna Coutsoudis, Hoosen M. Coovadia, et al.. Breast Health Problems Are Rare in Both HIV-Infected and HIV-Uninfected Women Who Receive Counseling and Support for Breast-Feeding in South Africa.. Clinical Infectious Diseases, 2007, 45 (11), pp.1502-10. 10.1086/523320 . inserm-00171008

\section{HAL Id: inserm-00171008 https://www.hal.inserm.fr/inserm-00171008}

Submitted on 5 Oct 2009

HAL is a multi-disciplinary open access archive for the deposit and dissemination of scientific research documents, whether they are published or not. The documents may come from teaching and research institutions in France or abroad, or from public or private research centers.
L'archive ouverte pluridisciplinaire HAL, est destinée au dépôt et à la diffusion de documents scientifiques de niveau recherche, publiés ou non, émanant des établissements d'enseignement et de recherche français ou étrangers, des laboratoires publics ou privés. 


\title{
Breast health problems are rare in both HIV-infected and uninfected women supported to exclusively breastfeed in South Africa
}

\author{
RM Bland ${ }^{1,2}$, R Becquet ${ }^{1,3,4}$, NC Rollins ${ }^{5}$, A Coutsoudis ${ }^{5}$, HM Coovadia $^{6}$, ML Newell ${ }^{1,7}$ \\ ${ }^{1}$ Africa Centre for Health and Population Studies, University of KwaZulu Natal, Somkhele, \\ South Africa \\ ${ }^{2}$ Division of Developmental Medicine, University of Glasgow, UK \\ 3 INSERM, Unité 593, Bordeaux, France \\ ${ }^{4}$ Institut de Santé Publique, Epidémiologie et Développement (ISPED), Université Victor \\ Segalen Bordeaux 2, Bordeaux, France \\ 5 Department of Paediatrics and Child Health, University of KwaZulu Natal, South Africa \\ ${ }^{6}$ Centre for HIV/AIDS Networking, University of KwaZulu Natal, South Africa \\ ${ }^{7}$ Centre for Paediatric Epidemiology and Biostatistics, Institute of Child Health, University \\ College London, UK
}

Short title: Breast health problems in South Africa

Key words: Exclusive breastfeeding, mastitis, HIV, breast health problems

Corresponding author: Dr Ruth Bland, Africa Centre for Health and Population Studies, PO Box 198, Mtubatuba, KwaZulu Natal, 3935, South Africa. Tel: +27 (0)35 550 7500; Fax: +27

(0)35 550 7565; e-mail: rbland@africacentre.ac.za

Alternate corresponding author: Professor Marie-Louise Newell, Africa Centre for Health and Population Studies, PO Box 198, Mtubatuba, KwaZulu Natal, 3935, South Africa. Tel: +27 (0)35 550 7500; Fax: +27 (0)35 550 7565; e-mail: mnewell@africacentre.ac.za

Word Count: 2528; Abstract: 250 


\begin{abstract}

\section{Background}

Breast problems, including mastitis, can interfere with the duration and exclusivity of breastfeeding. However, there are no large prospective studies documenting the prevalence, duration and timing of such problems in breastfeeding women, particularly those who are HIV-infected.
\end{abstract}

\title{
Methods
}

Women enrolled antenatally, were supported with a breastfeeding counselling intervention to 6 months post-delivery. Breast health problems were documented per breast for 180 days post-delivery, with 14-day recall histories.

\section{Results}

Breast health problems were rare and there were no significant differences between HIVinfected and uninfected women: engorgement 39 (3.5\%) vs. $33(2.7 \%), p=0.30$; breast thrush $17(1.5 \%)$ vs. $12(1.0 \%), p=0.25$; bleeding nipple $6(0.5 \%)$ vs. $4(0.3 \%), p=0.45$; mastitis/abscess $11(1.0 \%)$ vs. $6(0.5 \%), p=0.17$. Most problems occurred during the first month with few additional mothers experiencing problems after this: at 1 and 6 months, $13 \%$ and $17 \%$ of all mothers had experienced a minor or major breast health problem, including sore nipples, respectively. Women who had not exclusively breastfed their infant were more likely to experience any of the breast health problems (AOR 1.46, 95\% CI 1.13-1.87, $\mathrm{p}=0.003$, time dependent variable). HIV-infected women who experienced 
any serious breast health problem (bleeding nipple; nipple/breast oozing pus;

mastitis/abscess) were 3.55 (95\% CI, 0.86-14.78; $\mathrm{p}=0.08$ ) times more likely to transmit HIV postnatally to their infant.

\section{Conclusions}

With support to exclusively breastfeed, women experienced few breast health problems.

When they did occur, HIV-infected women with bleeding nipple, nipple or breast oozing pus, or mastitis/abscess were more likely to transmit HIV to their infants. 


\section{Introduction}

Mastitis and other breast health problems are commonly reported in breastfeeding women[1]. Whilst much is known about the clinical management of these problems[2, 3], there are limited reports about the expected prevalence of, or interventions to prevent, such conditions[1]. The reported incidence of mastitis and breast abscess varies from $2 \%[4,5]$ to $33 \%[6]$ of lactating women depending on study design, methods of data collection and selection of participants[1]. There are no large prospective cohort studies documenting the prevalence of breast pathologies in breastfeeding women.

Serious breast pathologies causing inflammation and bleeding, and also sub-clinical mastitis, have been associated with postnatal HIV transmission[7-10]. Additionally, conditions such as mastitis are known to interfere with the success and duration of optimal breastfeeding practice in the first six months i.e. exclusive breastfeeding[2-5]. On the other hand, exclusive breastfeeding decreases both mother-to-child transmission of HIV $[11,12]$ and breast health problems[2-5]. It is therefore necessary to understand the interactions between these three elements of infant feeding: breast health problems, exclusivity of breastfeeding and postnatal HIV transmission through breastfeeding. Breast problems in two cohorts of HIV-infected African women were reported to be high, with rates of mastitis during breastfeeding ranging from $11 \%[8]$ to $16 \%[9]$. Hence it is

critically important to prevent such breast health problems both to sustain exclusive breastfeeding and to reduce postnatal HIV transmission. 
We report on the prevalence, duration, timing and determinants of breast health problems in HIV-infected and uninfected women in rural and urban Africa who received an intervention designed to improve exclusive breastfeeding rates in the first six months post-partum. 


\section{Subjects and Methods}

HIV-infected and uninfected pregnant women attending nine clinics (eight rural and one urban) in KwaZulu Natal, South Africa, were enrolled into a non-randomised intervention cohort to examine breastfeeding and HIV transmission, and to investigate the feasibility of promoting exclusive breastfeeding in a community with a high prevalence of HIV-1 infection.

We previously described our infant feeding counselling and support strategy[11, 13, 14]. Briefly, lay HIV counsellors provided individual counselling to all pregnant women on infant feeding options according to WHO/UNAIDS recommendations at the antenatal clinic[15-17]. HIV-uninfected women were counselled to exclusively breastfeed for the first six months of life (180 days) with sustained breastfeeding to at least two years. The option of replacement feeding (commercial formula feeds) or exclusive breastfeeding for the first six months of life was discussed with HIV-infected women and women made decisions based on their home circumstances[13].

Lay breastfeeding counsellors, who were blinded to the HIV status of the women, visited all enrolled women at home to discuss feeding practices, study involvement and to meet other family members, if the women agreed. Women choosing to breastfeed were visited regularly at home by breastfeeding counsellors: up to four visits antentally; four visits in the first two weeks post-delivery; then once every two weeks to six completed months. At each postnatal visit the breastfeeding counsellors asked mothers to describe any breast 
health problems they had experienced, and documented these for each day between the current and last visit. If the problem was still present the breastfeeding counsellor observed the breast and a breastfeed, if the mother was able to feed from the affected side. Breast health problems for each breast were documented separately. The specific problems recorded were: painful nipple; cracked nipple; bleeding nipple; engorgement; blocked milk duct; breast thrush; nipple oozing pus; breast oozing pus; mastitis/abscess. Definitions, diagnosis and management of these problems were based on the WHO Breastfeeding Counselling Course and materials[3] (see Box 1).

The breastfeeding counsellors were trained on the WHO Breastfeeding Counselling Course[3], with structured support and mentoring thereafter. They received specific training on the diagnosis, management and appropriate referral of breast health problems. The breastfeeding counsellors dealt with painful nipples and breast thrush themselves (they carried nystatin cream on their field visits), but referred all other problems for a supervisor visit. The supervisors were chosen and promoted from the pool of breastfeeding counsellors, and received extra mentoring and clinical practice to enable them to solve more complex problems. A specialized nurse, with training on infant feeding counselling, was responsible for quality control in the field and problem-solving. Women with bleeding nipples, nipple/breast oozing pus, mastitis or an abscess, were referred immediately to the nearest clinic for assessment, antibiotic treatment if necessary, and appropriate infant feeding counselling: HIV-uninfected women were encouraged to continue to breastfeed whilst HIV-infected women were advised to stop breastfeeding from the affected breast until the problem resolved, but to maintain milk 
production by hand milk expression[17]. Women with any of the breast health problems were visited daily by the breastfeeding counsellors until the problem resolved.

In addition, field monitors visited all mothers weekly to document all feeds (milk and solids) and fluids for each day of the preceding week[11]. WHO definitions of infant feeding were used throughout the study[16]. Being exclusively breastfed at a given age meant having been fed with breastmilk only since birth (no water, other fluids or foods).

Women enrolled from the urban clinic received all their breastfeeding support and monitoring visits at the clinic, as it was not deemed safe for field workers to conduct home visits in this area. The study was approved by Biomedical Research Ethics Committee of the University of KwaZulu Natal.

\section{Statistical methods}

Women who delivered a live birth and initiated breastfeeding in the first two days after delivery were included in the analysis. Analysis was based on the database created on January $30^{\text {th }} 2007$.

Baseline characteristics were compared between HIV-infected and uninfected women using the Pearson $\chi^{2}$ test or the Fisher exact test to compare categorical variables, and the Mann-Whitney U test to compare continuous variables. The primary outcome was the 
occurrence of breast health problems over the first six months post-partum, documented individually, and then grouped together in three different ways: any of the breast health problems detailed in Box 1; any of these breast health problems excluding sore nipples; or any of the following problems: bleeding nipple, nipple or breast oozing pus, mastitis or breast abscess. The latter were grouped together as they are considered to be the most painful and serious of the breast health problems during breastfeeding, and have also been associated with postnatal HIV transmission[18].

The 6-month probability of remaining free from breast health problem (using the above mentioned three categorisations) was assessed by Kaplan-Meier method and its association with baseline maternal variables was quantified in univariate and multivariate stepwise Cox regression analyses[19, 20]. Only variables with a p value $<0.20$ in univariate analysis were included in multivariate analysis. In particular we examined whether women had exclusively breastfed or mixed breastfed prior to the occurrence of the breast health problem. When an infant received any other liquid or food other than breastmilk, they were removed from the exclusive breastfeeding category and considered to be mixed breastfed from that time onwards. Women who remained free from breast health problems were censored on the day when they completely ceased breastfeeding.

The effect of breast health problems on the risk of postnatal transmission of HIV was assessed in a Cox regression model. Children born to HIV-infected mothers with a negative RNA PCR from a sample obtained at age $\geq 1$ month and who later became HIVinfected were considered as HIV-infected postnatally[11]. The adjusted and unadjusted 
hazard ratios of occurrence of breast health problems on the risk of postnatal HIV transmission were calculated. This variable was time dependent, taking into account whether the breast health problem occurred before the acquisition of HIV by the infant. Adjustment was made on baseline maternal CD4 count (less vs. more than 200 cells/ml), maternal level of education (secondary school vs. primary school or none) and maternal employment in the formal economic sector.

All statistical analyses were carried out using SAS software (version 8.2; SAS Institute, http://www.sas.com). 


\section{Results}

2,755 women of known HIV status delivered a live infant, of whom 429 were excluded: 40 following infant death in week one, 152 who moved from the area/withdrew in week one; 47 with unknown feeding data during the first 2 days; and 190 women who did not breastfeed during the first two days. Therefore, 2,326 women are included in the analysis: 1,119 HIV-infected and 1,207 HIV-uninfected. There were no significant differences in basic socio-demographic characteristics between women included and excluded from the analyses.

Table 1 shows the baseline characteristics of women and children, and Table 2 the frequency, duration and timing of breast health problems in the first six months by maternal HIV status. Overall, serious breast problems were rare in HIV-infected and uninfected women. Whilst $16.9 \%$ of HIV-infected and $15.0 \%$ of uninfected women experienced any breast health problem (including sore nipples), only 1.8\% of HIVinfected and $0.9 \%$ of uninfected women experienced any serious breast health problem (i.e. bleeding nipple; nipple/breast oozing pus; mastitis; abscess).

Table 3 shows the 6-month probability of remaining free from breast health problems by maternal HIV status. Most breast health problems occurred during the first month with few additional mothers experiencing problems from 2-6 months: by 1 and 6 months, an estimated $13 \%$ and $17 \%$ of women would ever experience any minor or major breast health problem, including sore nipples, respectively. 
The probability of a woman having any breast health problem was associated with characteristics possibly indicating the intensity of support available (i.e. no home visits in urban areas, and women receiving fewer antenatal visits); and women who were not exclusively breastfeeding immediately prior to the breast health problem were more likely to have any breast health problem (Table 4). HIV-infected women were twice as likely to suffer from serious pathology as uninfected women and again non-exclusively breastfeeding was significantly associated with a more than doubling of the risk of the serious breast pathology.

\section{$\underline{\text { Postnatal transmission of HIV }}$}

The effect of breast health problems on the risk of postnatal transmission of HIV was assessed among the 860 children born to HIV-infected mothers who were HIV-negative in the peri-partum period. After adjustment on the baseline characteristics detailed in the Method section, postnatal transmission subsequent to breast health problems was more likely to occur than in the absence of breast health problems, especially in the case of serious pathology. Whereas HIV-infected women who ever experienced any breast health problem or any breast health problem excluding painful nipple were 1.68 (95\% CI, 0.972.94; $\mathrm{p}=0.05)$ and $1.88(95 \% \mathrm{CI}, 0.98-3.61 ; \mathrm{p}=0.06)$ times more likely to transmit HIV postnatally subsequently, women with serious breast health problems including bleeding nipple, nipple or breast oozing pus, mastitis or abscess, were 3.55 (95\% CI, 0.86-14.78; $\mathrm{p}=0.08)$ times more likely to transmit than those without breast health problems. 


\section{Discussion}

Our findings show a low prevalence of all breast health problems, particularly the more serious diagnoses (mastitis and abscess), compared to other reports[6, 8, 9], and to findings in our area prior to the implementation of the breastfeeding intervention, where $19 \%$ of women complained of a breastfeeding difficulty at some time between birth and 16 weeks post-delivery [21]. These low rates are most likely due to the quality of support the women received, and the high rates of exclusive breastfeeding achieved. At the antenatal visits, counsellors discussed with mothers the importance of giving colostrum to their infant and feeding on demand, with no restriction on the length or frequency of feeds[1]. They explained the difference between colostrum and later mature milk, and how to avoid engorgement by regular feeding and allowing the infant to finish feeding from one breast before offering the second breast[1]. During the early postnatal visits, breastfeeding counsellors observed breastfeeds and helped with positioning and attachment of the infant at the breast, and diagnosed early problems (for example sore nipples due to poor attachment) before they developed into more serious problems (for example, cracked nipple, bleeding nipple). Most problems occurred during the first month, and it is at this time that breastfeeding women need support and help to establish breastfeeding. Women who received fewer of the scheduled antenatal visits were more likely to experience any breast health problems, as were women who had not exclusively breastfed immediately prior to the occurrence of the problem. Women who had not breastfed previously were more likely to experience problems, highlighting the importance of support for primiparous women. There is no clear explanation for the fact 
that women without piped water were more likely to experience problems. It is possible that these women, who were socio-economically disadvantaged, lived further from the clinics and had less access to immediate support. Alternatively these women may have spent significant portions of their day walking to collect water which may have interfered with demand breastfeeding, if their infants were left behind, and thus led to milk stasis and breast health problems.

Our study design gave us the opportunity to explore differences in breast health problems in women who received home counselling visits (in the rural and peri-urban areas) and those who received counselling at the clinics (urban area). Whilst women in the urban area were more likely to experience any breast health problem; they were not more likely to experience serious breast health pathology. This has important public health implications as clinic-based support for infant feeding is immediately feasible at a large scale and could be complemented by community health worker home visits where available.

The strengths of this study are the prospective documentation of breast health problems in a large cohort of HIV-infected and uninfected women, documented daily for 180 days with 14-day recall histories; a daily record of infant feeding practices with 7-day recall histories; and use of standardized WHO infant feeding definitions. Under these stringent conditions, there were no significant differences in the occurrence of any breast health problems between HIV-infected and uninfected women. This is not surprising as most breast health problems result from practical difficulties, such as inefficient removal of 
milk resulting from poor breastfeeding technique, as opposed to bacterial infection[1, 3 , 22, 23]. It is, perhaps, surprising, that breast thrush was equally common amongst HIVinfected and uninfected women, as one would expect this condition to be associated with immunosuppression.

When the more serious breast conditions were grouped together (bleeding nipple, nipple or breast oozing pus, mastitis or abscess) there was a significant difference between HIVinfected and uninfected women, but the prevalences were still very low. Despite this, and the prompt management of problems by the breastfeeding counsellors, HIV-infected women with these problems were significantly more likely to transmit HIV to their infant. It is crucial to prevent these conditions occurring in all women, but particularly in those who are HIV-infected. It is also important that health workers managing these problems understand the differences in management between women who are HIVinfected and uninfected - encouraging HIV-uninfected women to continue breastfeeding, but advising HIV-infected women to express and discard milk from the affected side until the problem resolves[16, 24].

Lay breastfeeding counsellors, with no tertiary education, who received practical training on breast feeding, followed by supervision and mentoring, were able not only to support exclusive breastfeeding, but also to reduce the rates of breast health problems. As these problems cause a considerable burden of disease in breastfeeding women and may involve substantial costs to the health services, prevention and rapid, effective, treatment of breastfeeding problems is of great importance. 


\section{Acknowledgements}

Wellcome Trust supported this study (Grant \#063009/Z/00/2) and the Africa Centre (Grant \#050534). Renaud Becquet was funded by the French charity SIDACTION as a visiting epidemiologist at the Africa Centre for Health and Population Studies (University of KwaZulu Natal, South Africa). None of the authors have a conflict of interest.

We are grateful to all women and children enrolled in the study and the continued dedication of field, clinic and data management staff at the Africa Centre, in particular Thembi Blose, Zanele Fakude, Cookie Govender, Nqobile Mkhwanazi, Londiwe Mthethwa, Samukelisiwe Mtshali and Ntombizodumo Mkwanazi. We are also grateful to Colin Newell who assisted with data management during the study and analyses; Dave Perlman and Kobus Herbst for their assistance in the design of the database; Geoff Solarsh, Shuaib Kauchali, Ameena Goga, Jane Lucas and Felicity Savage King for assistance in the initial formative work and training. In particular we wish to thank the Community Liaison Office of the Africa Centre and the Community Advisory Board for their guidance and feedback throughout the study.

We are also grateful to the independent members of the Study Steering Committee and the Data Monitoring and Safety Committee: Janet Darbyshire (Chair, MRC, UK), Nono Simelela (SA Department of Health), Victoria Sithole (Community Advisory Board). Data Monitoring and Safety Committee: Cathy Wilfert (Chair, Elizabeth Glaser Pediatric AIDS Foundation), Carl Lombard (Statistician, MRC, SA), Ames Dhai (Department of 
Obstetrics and Gynaecology and the Biomedical Ethics Unit, UKZN) and Francis Crawley (Good Clinical Practice Alliance). 


\section{Box 1: Definitions of breast health conditions $[3,22]$}

\begin{tabular}{|c|c|}
\hline Painful nipple & Mother complains of pain in her nipple. \\
\hline Cracked nipple & A fissure or crack anywhere on the nipple, including the base. \\
\hline Bleeding nipple & Blood coming from the nipple. \\
\hline Engorgement & $\begin{array}{l}\text { Painful, oedematous breasts, usually bilateral. The skin of the breasts, } \\
\text { especially nipples, looks tight and shiny. Milk does not flow easily; the } \\
\text { mother may experience fever for } 24 \text { hours. }\end{array}$ \\
\hline Blocked milk duct & $\begin{array}{l}\text { A lump, often tender, sometimes with inflammation of the overlying skin. } \\
\text { The woman has no fever and feels well. }\end{array}$ \\
\hline Breast thrush & $\begin{array}{l}\text { Skin of nipple and areola is shiny and flaky (also noted to be red on paler } \\
\text { skin); there is itchiness. Mother often complains of deep pain which } \\
\text { persists between feeds. }\end{array}$ \\
\hline Nipple oozing pus & Pus coming from the nipple. \\
\hline Breast oozing pus & Pus coming from the breast (as opposed to the nipple). \\
\hline Mastitis & $\begin{array}{l}\text { Part of the breast is swollen and hard, with inflammation of the overlying } \\
\text { skin. Mother complains of severe pain, fever and feels ill. }\end{array}$ \\
\hline Abscess & $\begin{array}{l}\text { A localized, painful, collection of pus within the breast. Mother } \\
\text { complains of severe pain, fever and feels ill. }\end{array}$ \\
\hline
\end{tabular}


Table 1: Baseline characteristics of women and children according to maternal HIV status

\begin{tabular}{|c|c|c|c|}
\hline Characteristic & $\begin{array}{l}\text { HIV-positive women } \\
n=1,119\end{array}$ & $\begin{array}{l}\text { HIV-negative women } \\
n=1,207\end{array}$ & p value \\
\hline Maternal age, median (IQR) & $25(21-29)$ & $22(19-28)$ & $<0.001$ \\
\hline \multicolumn{4}{|l|}{ Residence } \\
\hline Urban & $195(17.4)$ & $185(15.3)$ & $<0.001$ \\
\hline Peri-urban & $413(36.9)$ & $347(28.8)$ & \\
\hline Rural & $511(45.7)$ & $675(55.9)$ & \\
\hline \multicolumn{4}{|l|}{ Highest education achieved, n (\%) } \\
\hline Secondary & $621(50.5)$ & $728(60.3)$ & 0.06 \\
\hline Primary & $422(37.7)$ & $407(33.7)$ & \\
\hline None & $76(6.8)$ & $72(6.0)$ & \\
\hline \multicolumn{4}{|l|}{ Mother currently at school, $\mathrm{n}(\%)^{\mathrm{a}}$} \\
\hline Yes & $43(3.9)$ & $103(8.6)$ & $<0.001$ \\
\hline No & $1070(96.1)$ & $1100(91.4)$ & \\
\hline \multicolumn{4}{|l|}{ Source of water, $\mathrm{n}(\%)^{\mathrm{a}}$} \\
\hline Piped water inside home & $81(7.3)$ & $91(7.6)$ & 0.58 \\
\hline Piped water outside & $673(60.5)$ & $748(62.2)$ & \\
\hline Other source of water & $359(32.2)$ & $364(30.2)$ & \\
\hline \multicolumn{4}{|l|}{ Toilet, $\mathrm{n}(\%)^{\mathrm{a}}$} \\
\hline Flush toilet & $186(15.5)$ & $191(17.2)$ & 0.32 \\
\hline Other form sanitation & $712(59.2)$ & $665(59.7)$ & \\
\hline No toilet & $305(25.3)$ & $257(23.1)$ & \\
\hline \multicolumn{4}{|l|}{ Mother is main income provider, $\mathrm{n}(\%)^{\mathrm{a}}$} \\
\hline Yes & $116(10.4)$ & $73(6.1)$ & $<0.001$ \\
\hline No & $997(89.6)$ & $1130(93.9)$ & \\
\hline $\begin{array}{l}\text { Antenatal maternal CD4 count } \times 10^{6} \text { cells } / \mathrm{ml} \text {, median } \\
(\mathrm{IQR})^{\mathrm{b}}\end{array}$ & $467(318-637)$ & - & - \\
\hline $\begin{array}{l}\text { Antenatal maternal } \log _{10} \text { plasma HIV RNA viral load, } \\
\text { median (IQR) }\end{array}$ & $4.0(3.3-4.6)$ & - & - \\
\hline Number of previous liveborn children, median (IQR) ${ }^{a}$ & $1(0-2)$ & $0(0-2)$ & 0.03 \\
\hline \multicolumn{4}{|l|}{ Previous breastfeeding experience } \\
\hline Women with previous liveborn child, n (\%) & $732(65.4)$ & $599(49.6)$ & $<0.001$ \\
\hline Women who breastfed him/her, n (\%) & $732(100)$ & $599(100)$ & 1.0 \\
\hline $\begin{array}{l}\text { Duration of previous breastfeeding, median in } \\
\text { months (IQR) }\end{array}$ & $18(12-24)$ & $18(12-24)$ & 0.27 \\
\hline \multicolumn{4}{|l|}{ Mode of delivery, $\mathrm{n}(\%)^{\mathrm{a}}$} \\
\hline Caesarean section & $131(11.8)$ & $145(12.0)$ & 0.86 \\
\hline \multirow{2}{*}{\multicolumn{4}{|c|}{ Place of delivery, $\mathrm{n}(\%)^{\mathrm{a}}$}} \\
\hline & & & \\
\hline Facility (hospital or clinic) & $949(85.8)$ & $1051(87.5)$ & 0.22 \\
\hline Home & $157(14.2)$ & $150(12.5)$ & \\
\hline \multicolumn{4}{|l|}{ Child gender, n (\%) } \\
\hline Male & $566(50.6)$ & $601(49.8)$ & 0.70 \\
\hline Female & $553(49.4)$ & $606(50.2)$ & \\
\hline Child birthweight, median in grams (IQR) ${ }^{\mathrm{d}}$ & $3,100(2,750-3,500)$ & $3,200(2,900-3,600)$ & $<0.001$ \\
\hline Child still breastfed at 180 days of age, n (\%) & $666(59.5)$ & $877(72.7)$ & $<0.001$ \\
\hline $\begin{array}{l}\text { Child exclusively breastfed from birth to } 180 \text { days of } \\
\text { age, } n(\%)\end{array}$ & $472(42.2)$ & $540(45.7)$ & 0.21 \\
\hline
\end{tabular}


Table 2: Frequency and duration of breast health problems in the first 6 months according to maternal HIV status

\begin{tabular}{|c|c|c|c|}
\hline Diagnosis of breast health problem & $\begin{array}{c}\text { HIV-positive } \\
\text { women } \\
n=1,119\end{array}$ & $\begin{array}{c}\text { HIV-negative } \\
\text { women } \\
\text { n=1,207 }\end{array}$ & p value \\
\hline \multicolumn{4}{|l|}{ Sore nipples } \\
\hline Women ever experienced this problem, n (\%) & $99(8.9)$ & $101(8.4)$ & 0.68 \\
\hline No. of days with problem, median (IQR) & $2(1-4)$ & $2(2-4)$ & 0.38 \\
\hline First day of occurrence postnatally, median (IQR) & $3(1-16)$ & $3(2-7)$ & 0.44 \\
\hline \multicolumn{4}{|l|}{ Engorgement } \\
\hline Women ever experienced this problem, n (\%) & $39(3.5)$ & $33(2.7)$ & 0.30 \\
\hline No. of days with problem, median (IQR) & $1(1-3)$ & $2(1-2)$ & 0.29 \\
\hline First day of occurrence postnatally, median (IQR) & $5(3-29)$ & $3(3-5)$ & 0.005 \\
\hline \multicolumn{4}{|l|}{ Breast thrush } \\
\hline Women ever experienced this problem, n (\%) & $17(1.5)$ & $12(1.0)$ & 0.25 \\
\hline No. of days with problem, median (IQR) & $5(3-8)$ & $12(7-17)$ & 0.16 \\
\hline First day of occurrence postnatally, median (IQR) & $99(50-116)$ & $70(51-127)$ & 0.87 \\
\hline \multicolumn{4}{|l|}{ Blocked duct } \\
\hline Women ever experienced this problem, n (\%) & $23(2.1)$ & $24(2.0)$ & 0.91 \\
\hline No. of days with problem, median (IQR) & $3(2-7)$ & $3(2-3)$ & 0.12 \\
\hline First day of occurrence postnatally, median (IQR) & $20(11-57)$ & $21(4-47)$ & 0.79 \\
\hline \multicolumn{4}{|l|}{ Cracked nipple } \\
\hline Women ever experienced this problem, n (\%) & $38(3.4)$ & $33(2.7)$ & 0.35 \\
\hline No. of days with problem, median (IQR) & $4(2-7)$ & $3(2-6)$ & 0.23 \\
\hline First day of occurrence postnatally, median (IQR) & $13(3-62)$ & $7(3-25)$ & 0.47 \\
\hline \multicolumn{4}{|l|}{ Bleeding nipple } \\
\hline Women ever experienced this problem, n (\%) & $6(0.5)$ & $4(0.3)$ & 0.45 \\
\hline No. of days with problem, median (IQR) & $2(1-2)$ & $1(1-2)$ & 0.24 \\
\hline First day of occurrence postnatally, median (IQR) & $6(2-28)$ & $8(2-26)$ & 0.47 \\
\hline \multicolumn{4}{|l|}{ Nipples oozing pus } \\
\hline Women ever experienced this problem, n (\%) & $2(0.2)$ & 0 & 0.23 \\
\hline No. of days with problem, median (IQR) & ${ }^{*} 2^{: 1} ; 5^{: 1}$ & - & - \\
\hline First day of occurrence postnatally, median (IQR) & ${ }^{*} 1^{: 1} ; 15^{: 1}$ & - & - \\
\hline \multicolumn{4}{|l|}{ Breast oozing pus } \\
\hline Women ever experienced this problem, n (\%) & $2(0.2)$ & $1(0.1)$ & 0.36 \\
\hline No. of days with problem, median (IQR) & ${ }^{*} 1^{: 1} ; 10^{: 1}$ & ${ }^{*}: 1$ & - \\
\hline First day of occurrence postnatally, median (IQR) & $* * 68^{: 1} ; 80^{: 1}$ & *** $156^{: 1}$ & - \\
\hline \multicolumn{4}{|l|}{ Mastitis or abscess } \\
\hline Women ever experienced this problem, n (\%) & $11(1.0)$ & $6(0.5)$ & 0.17 \\
\hline No. of days with problem, median (IQR) & $7(5-14)$ & $8(7-13)$ & 0.49 \\
\hline First day of occurrence postnatally, median (IQR) & $17(7-23)$ & $5(24-54)$ & 0.32 \\
\hline \multicolumn{4}{|l|}{ Any of above diagnoses } \\
\hline Women ever experienced these problems, n (\%) & $189(16.9)$ & $181(15.0)$ & 0.21 \\
\hline \multicolumn{4}{|l|}{ Any of above diagnoses excluding sore nipples } \\
\hline Women ever experienced these problems, n (\%) & $114(10.1)$ & $102(8.5)$ & 0.15 \\
\hline \multicolumn{4}{|l|}{$\begin{array}{l}\text { Any of following diagnoses: bleeding nipple, nipple or } \\
\text { breast oozing pus, mastitis or abscess }\end{array}$} \\
\hline Women ever experienced these problems, n (\%) & $20(1.8)$ & $11(0.9)$ & 0.07 \\
\hline
\end{tabular}

$\mathrm{IQR}=$ interquartile range $\left(25^{\text {th }}\right.$ and $75^{\text {th }}$ percentiles $) ;{ }^{*} \mathrm{x}^{: 1}=1$ woman, for whom the problem lasted for $\mathrm{x}$ days; ${ }^{*} \mathrm{x}^{: 1}=1$ woman, for whom the problem started on day $\mathrm{x}$ 
Table 3: Kaplan-Meier probability of remaining free from breast health problems according to maternal HIV status

Probability (95\% CI) of remaining free from

Age 1 Month

Age 3 Months

Age 6 Months

$p$ value

(Log-Rank Test)

Any breast health problem

HIV-negative mothers

$0.87(0.85-0.89)$

$0.85(0.83-0.87)$

$0.84(0.82-0.86)$

0.13

HIV-positive mothers

$0.87(0.85-0.89)$

$0.84(0.82-0.86)$

$0.81(0.79-0.84)$

Any breast health problem, excluding sore nipples

HIV-negative mothers

$0.94(0.92-0.95)$

$0.92(0.90-0.93)$

$0.93(0.91-0.94)$

$0.91(0.89-0.92)$

$0.91(0.89-0.93)$

0.08

HIV-positive mothers

Bleeding nipple, nipple or breast oozing pus, mastitis or abscess

HIV-negative mothers

0.99 (0.99-1.00)

$0.99(0.98-1.00)$

0.98 (0.97-0.99)

0.98 (0.97-0.99)

$0.99(0.98-0.99)$

0.98 (0.97-0.99)

0.05 
Table 4: Determinants of occurrence of a breast health problem

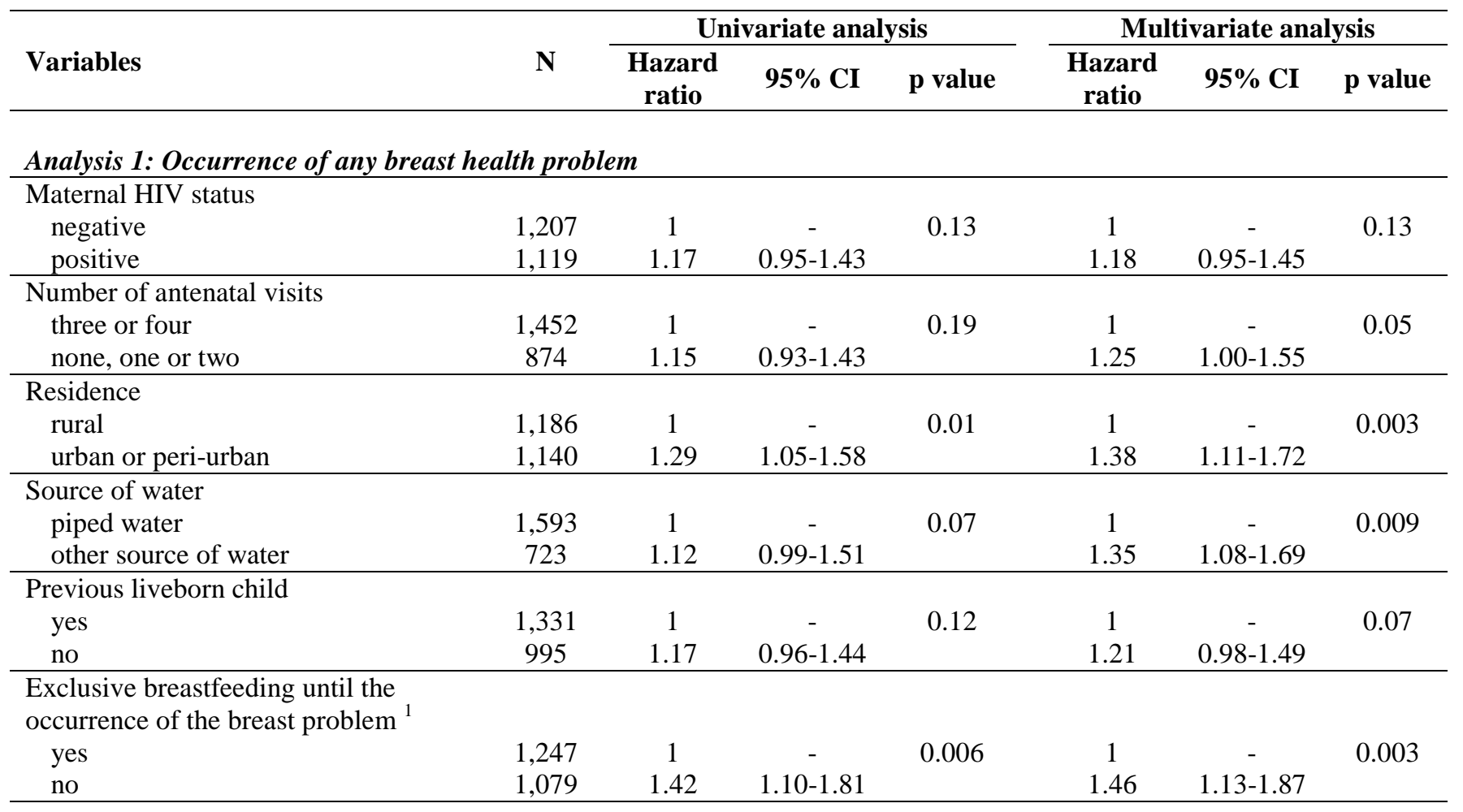

\begin{tabular}{|c|c|c|c|c|c|c|c|}
\hline $\begin{array}{l}\text { Maternal HIV status } \\
\text { negative } \\
\text { positive }\end{array}$ & $\begin{array}{l}1,207 \\
1,119\end{array}$ & $\begin{array}{c}1 \\
1.27\end{array}$ & $\begin{array}{c}- \\
0.97-1.66\end{array}$ & 0.08 & $\begin{array}{c}1 \\
1.21\end{array}$ & $\begin{array}{c}- \\
0.92-1.58\end{array}$ & 0.17 \\
\hline $\begin{array}{l}\text { Residence } \\
\text { rural } \\
\text { urban or peri-urban }\end{array}$ & $\begin{array}{l}1,186 \\
1,140\end{array}$ & $\begin{array}{c}1 \\
1.31\end{array}$ & $\begin{array}{c}- \\
1.00-1.72\end{array}$ & 0.05 & $\begin{array}{c}1 \\
1.38\end{array}$ & - & 0.02 \\
\hline $\begin{array}{l}\text { Source of water } \\
\text { piped water } \\
\text { other source of water }\end{array}$ & $\begin{array}{c}1,593 \\
723\end{array}$ & $\begin{array}{c}1 \\
1.28\end{array}$ & $\begin{array}{c}- \\
0.97-1.69\end{array}$ & 0.09 & $\begin{array}{c}1 \\
1.41\end{array}$ & - & 0.02 \\
\hline $\begin{array}{l}\text { Exclusive breastfeeding until the } \\
\text { occurrence of the breast problem }{ }^{1} \\
\text { yes } \\
\text { no }\end{array}$ & $\begin{array}{l}1,181 \\
1,145\end{array}$ & $\begin{array}{c}1 \\
1.40\end{array}$ & $\begin{array}{c}- \\
1.03-1.91\end{array}$ & 0.03 & $\begin{array}{c}1 \\
1.42\end{array}$ & $\begin{array}{c}- \\
1.04-1.93\end{array}$ & 0.02 \\
\hline
\end{tabular}

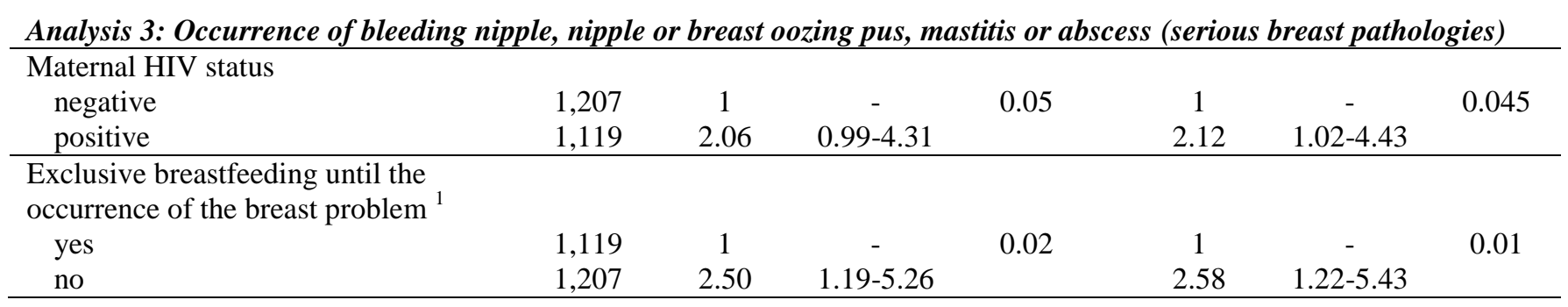

${ }^{1}$ Time dependent variable 


\section{References}

1. World Health Organization. Mastitis: Causes and management.Geneva:WHO/FCH/CAH. 13, 2000.

2. Lawrence RA. Breastfeeding: a guide for the medical profession. 4th ed. St. Louis: Mosby, 1994.

3. WHO/UNICEF. Breastfeeding counselling: A training course. Trainer's Guide: World Health Organization, Geneva, 1993.

4. Kaufmann R, Foxman B. Mastitis among lactating women: occurrence and risk factors. Soc Sci Med 1991;33(6):701-5.

5. Prentice A, Prentice A, Lamb W. Mastitis in rural Gambian mothers and the proection of the breast by milk antimicrobial factors. Trans R Soc Trop Med Hyg 1985;79(1):90-5.

6. Riordan J, Nichols F. A descriptive study of lactation mastitis in long-term breastfeeding women. J Hum Lact 1990;6(2):53-8.

7. Embree JE, Njenga S, Datta P, et al. Risk factors for postnatal mother-child transmission of HIV-1. AIDS 2000 Nov 10;14(16):2535-41.

8. John GC, Nduati RW, Mbori-Ngacha DA, et al. Correlates of mother-to-child human immunodeficiency virus type 1 (HIV-1) transmission: association with maternal plasma HIV-1 RNA load, genital HIV-1 DNA shedding, and breast infections. J Infect Dis 2001 Jan 15;183(2):206-12.

9. Semba RD, Kumwenda N, Hoover DR, et al. Human immunodeficiency virus load in breast milk, mastitis, and mother-to-child transmission of human immunodeficiency virus type 1. J Infect Dis $1999 \mathrm{Jul} ; 180(1): 93-8$.

10. Willumsen JF, Filteau SM, Coutsoudis A, et al. Breastmilk RNA viral load in HIV-infected South African women: effects of subclinical mastitis and infant feeding. AIDS 2003 Feb 14;17(3):407-14.

11. Coovadia H, Rollins N, Bland R, et al. Mother-to-child transmission of HIV-1 infection during exclusive breastfeeding: the first six months of life. Lancet 2007;369:1607-16.

12. Illiff P, Piwoz E, Tavengwa NV, et al. Early exclusive breastfeeding reduces the risk of postnatal HIV-1 transmission and increases HIV-free survival. AIDS 2005; 19:699-708.

13. Bland R, Rollins N, Coovadia H, Coutsoudis A, Newell M. Infant feeding counselling for HIV-infected and uninfected women: appropriateness of choice and practice. Bull WHO 2007;85:289-96.

14. Bland RM, Newell M, Rollins N, Coutsoudis A, Coovadia H. WHO and UNICEF infant feeding policy for HIV-positive women - how feasible is it? In: TUPEO342, XVI International Aids Conference, Toronto, 13-18 August, 2006.

15. WHO. New data on the prevention of mother-to-child transmission of HIV and their policy implications. Conclusions and recommendations. WHO technical consultation on behalf of the UNFPA/UNICEF/WHO/UNAIDS Inter-agency task team on mother-to-child transmission of HIV, 11-13 October 2000. 2001.

16. WHO, UNICEF, UNAIDS, UNFPA. HIV and infant feeding: A guide for healthcare managers and supervisors: World Health Organization, Geneva, 2003. 
17. WHO/UNICEF/UNAIDS. HIV and infant feeding counselling: a training course. Trainers' Guide. 2000.

18. WHO, UNICEF, UNAIDS, UNFPA. HIV transmission through breastfeeding: A review of available evidence: World Health Organization, Geneva, 2004.

19. Cox D, Oakes D. Analysis of survival data. 1984.

20. Kaplan E, Meier P. Nonparametric estimation from incomplete observations. J Am Statist Assoc 1958;53:457-81.

21. Bland R, Rollins N, Coutsoudis A, Coovadia H. Breastfeeding practices in an area of high HIV prevalence in rural South Africa. Acta Paediatr 2002;91(6):704-11.

22. Savage-King F. Helping mothers to breastfeed: African Medical and Research Foundation (AMREF), Nairobi, 1992.

23. Woolridge MW. Aetiology of sore nipples. Midwifery 1986 Dec;2(4):172-6.

24. WHO/UNICEF. Infant and Young Child Feeding Counselling: An Integrated Course: World Health Organization, Geneva, 2006. 